\title{
Strategies In Maximizing The Implementation Of Industrialised Building System (Ibs) In Construction Projects In Petaling Jaya, Selangor Darul Ehsan
}

\author{
Mashanim Mahazir ${ }^{\mathbf{x}}$, Ng Zhiong Kam ${ }^{1}$ \\ ${ }^{1}$ Faculty of Engineering \& the Built Environment \\ SEGi University, Kota Damansara, Selangor Darul Ehsan, Malaysia \\ mashanim@segi.edu.my
}

\begin{abstract}
The implementation of Industrialized Building Systems (IBS) has been introduced in Malaysian construction industries since early 1960s and the government has successfully launched the first IBS project which was known as Pekeliling Flats, Kuala Lumpur with low cost and affordable project. The survey conducted by CIDB Malaysia indicated that the adoption of IBS in local construction industry still considered as not reach to the satisfaction level although the adoption of IBS have been intensively introduced and promoted by the government and private sectors from the early stage. The usage of IBS still remains low definitely due to the barriers that hinder the implementation of IBS in the construction industries. Research was conducted using quantitative research approach through questionnaire surveys. The analysis method is mainly derived from descriptive analysis. Thus, this study is conducted to improve the adoption of IBS in local construction industry by identifying the main factors and current awareness on the usage of IBS. This study also concentrates to improve the strategies with the purpose to maximize the implementation of IBS in Malaysian construction industries. More effective strategies will be generated to enhance the rate of IBS adoption and minimize the barriers to the minimum level.
\end{abstract}

\section{Introduction}

In the era of globalization, construction industry is generally developing rapidly towards the modernization sector. Nowadays, construction industries in Malaysia are also no exception in the efforts of pushing forward into the industrialized country in order to achieve 
the Vision 2020 launched by the Ex-Prime Minister YAB Tun Dato' Seri Dr Mahathir bin Mohamad. With the rapid growth of economy and population in Malaysia, the demand for the market in construction industries is relatively increasing especially for the residential development projects. Thus, the government has launched the affordable and medium cost housing projects in the way to meet the highly demands required by the communities in Malaysia. However, the common practice of conventional method mostly adopted in the Malaysian construction industries is definitely slow down the construction process. The solution to overcome this problem issue is by the introduction of Industrialized Building System (IBS) to be implemented in the construction projects in Malaysian construction industries.

IBS is a construction method whereby the components are prefabricated and manufactured off-site in the factories, transported to the site and assembled by the advanced technology machinery and skilled workers with minimum time and works on site. For the IBS components, it is divided into five major types which comprising of precast concrete framing, panel and box systems, steel formwork systems, steel framing systems, prefabricated timber framing systems and block systems (Construction industry development board (CIDB Malaysia, 2003). These prefabrication components are designed and manufactured in standardization and ready to be transported and assembled on site which results in reduction of working time and fewer workers required.

The IBS in Malaysian construction industry is not considered as new system as it was introduced since early 1960. According to CIDB, the Malaysian government has successfully launched the first IBS project with low cost building at Jalan Pekeliling known as Pekeliling Flats in Kuala Lumpur and the Rifle Range Road Flats in Penang in 19661968 by using precast elements. The IBS Roadmap 2003 - 2010 has been endorsed by the Cabinet of Ministers to be the blueprint document for the industrialization of the Malaysian construction sector (CIDB, 2003). The IBS has been promoted widely by the Construction Industry Development Board of Malaysia (CIDB) in the Malaysian construction industry since 1998. However, the percentage 
for the usage of IBS for construction projects is still in low level. From a survey conducted by CIDB Malaysia, the usage level of IBS in the local construction industry stands at only $15 \%$ (CIDB, 2003). The undesirable result obtained based on the IBS Survey 2003 showed that $85 \%$ of the construction industry practitioners still rely on the conventional construction method.

There are several factors that restrict the usage of IBS to be implemented by the construction industry in Selangor, Malaysia. The primary factor is the low cost foreign labour to be hired in a huge amount to work in the local construction industries. Thus, the major purpose to promote the IBS is to minimize the dependency of foreign labour in order to develop the Malaysian construction industries towards high quality, productivity and safety. Indeed, the implementation of IBS provides benefits to the construction industry. The IBS, which enables on-site prefabricated or pre-cast building components manufactured at factories, will enable cost saving and quality improvement through the reduction of labour intensity and construction standardization (CIDB, 2003). In addition, it provides environmental friendly by the reduction of construction wastes such as timber formworks, concrete and aggregate, thus enhance the construction cost to be reduced.

Integration between government sector and private sector in the efforts to expose the awareness and strategy to improve and maximize the implementation of IBS construction project in Selangor, Malaysia is equally important to enhance the local construction development towards the global competitiveness.

\section{Research Method}

The study was conducted in Petaling Jaya, Selangor in maximizing the usage of IBS in construction projects. There were 275 consultants took part in the surveys conducted. 152 questionnaires were collected out of 275 distributed. Qualitative and quantitative methods were used to conduct the research. All data obtained were analyzed using SPSS software. Data was examined by using descriptive analysis. 


\section{Data Analysis And Findings}

\section{A. Demographic data}

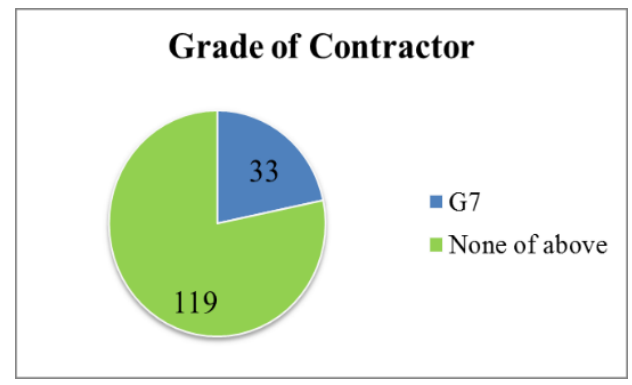

Figure 1. Grade of the respondents (contractor)

Figure 1 showed the results on the grade of Contractor for the respondents in the construction industry. There are 33 respondents are the Contractors with the grade of G7 in the CIDB registration list. However, there are 119 respondents are not the Contractors with any grade which represented the other construction parties in the G7 Contractors' firms.

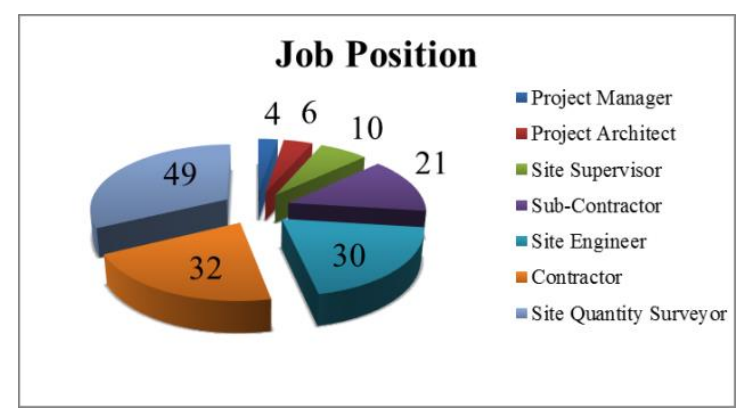

Figure 2. Position of the respondent

Based on the results showed in Figure 2, it can be found that most of the respondents to conduct the research are Site Quantity Surveyors with are 49 of 152 respondents. The second highest are the Contractors with 32 respondents and followed by Site Engineer with 30 respondents. Besides, there are 21 respondents are the SubContractors, 10 respondents are the Site Supervisors and followed by 6 respondents are the Project Architects. There are only 4 respondents are the Project Managers. 


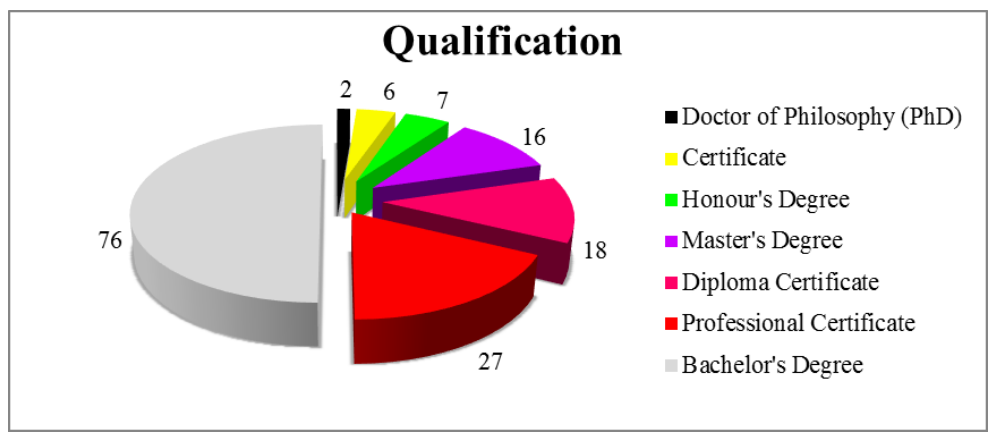

Figure 3. Qualification of the respondent

According to Figure 3, there are 76 respondents have the qualification of education for Bachelor's Degree and followed by 27 respondents have the Professional Certificate. Next, there are 18 respondents having the Diploma Certificate and 16 respondents are the Master's Degree holders. In addition, there are 7 respondents are the Honour's Degree holders and followed by 6 respondents with Certificate. Lastly, there are only 2 respondents have the Doctor of Philosophy $(\mathrm{PhD})$ among 152 respondents from this research.

\section{B. Analysis and findings}

Responsibility of construction parties to IBS.

Figure 4 expressed the results for the construction parties are responsible for the implementation of IBS in construction industry based on the level of agreement by the respondents. The position of the construction parties have been arranged based on the value of mean obtained. Figure IV presented that all of the respondents agree and strongly agree that designer is the main construction party that should responsible for the implementation of IBS with the highest mean score of 4.30 among the other construction parties. The reason that the designer has the highest responsibility to implement IBS is because of mostly the designers are from the Architects and Structural Engineers. They play the significant roles in designing the various types IBS components to avoid any improper planning in their design or other problems that could lead the barriers for the implementation of IBS. 
The second highest rank with the mean score of 4.25 is the manufacturer. Manufacturer should responsible for the implementation of IBS because the IBS components are required to be manufactured off-site in the factory before transported to the site for installation works. The following is the Contractor with the mean score of 4.24. Contractors are considered as the significant parties that should responsible for the adoption of IBS because they have the role to transform the conventional construction method to IBS method with the aim to produce high quality and effective works in the local construction industry in order to meet the qualification to compete in this mechanization era. Next, developer is positioned in the fourth place with the mean score of 3.81. Developer is also considered as part of the construction party that should contribute to the implementation of IBS in private construction sector.

However, most of the respondents disagree that the supplier, subcontractor and project manager have the responsibility to the implementation of IBS. The mean score for supplier is 2.61, subcontractor with 2.59 and 2.49 for project manager that ranked in the lower position. It can be concluded that supplier, sub-contractor and project manager are not considered as the significant construction parties that should responsible to the implementation of IBS.

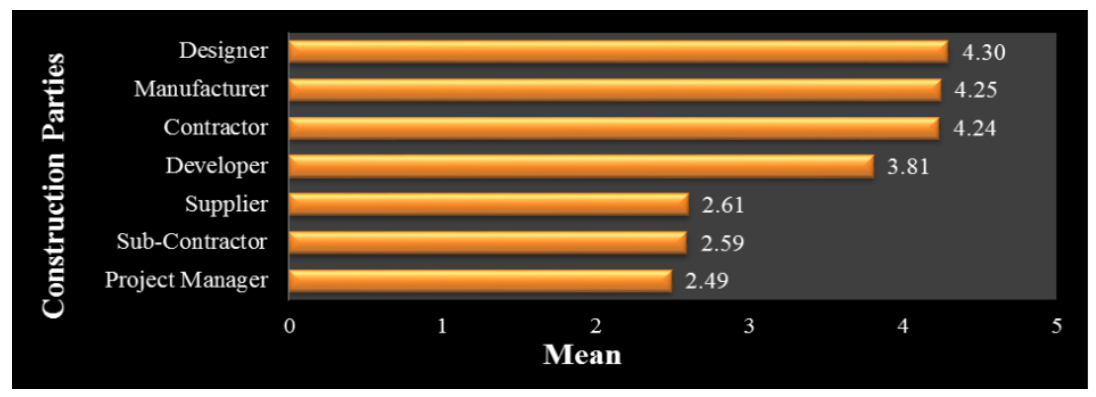

Figure 4. Responsibility of construction parties to IBS.

Construction parties that should involve in IBS

Figure 5 showed the results on the level of importance for each construction parties which should involve in the implementation of IBS in construction industry based on the understanding of the respondents. The results have been analyzed according to the value of 
mean obtained. All the respondents agreed that the manufacturer is the most important construction party which should involve in the implementation of IBS with the highest mean score of 4.49. This is because the manufacturer for IBS is mainly to fabricate most of the IBS precast components that required to be installed on site.

The second highest position with the mean score of 4.47 is the designer. Involvement of the designers is very important to ensure that all the precast components can be designed properly and able to fulfill the client's requirements. The third highest rank is the Contractor with the mean score of 4.45 due to the reason that the Contractors are the one to construct the building and have the connection with all the construction parties involved in the IBS project which playing the main role to influence the perspective of the construction parties on the adoption of IBS. Next, the developer achieved the mean score of 4.21 which ranked in the fourth positioned. The contribution of developer to the implementation of IBS in the private construction sector is very important which could increase the rate for the adoption of IBS in the local construction industry.

In addition, most of the respondents responded that the supplier is an important party that should involve in the implementation of IBS with the mean score of 3.88. All the precast components will be ordered by the Contractors from the suppliers in order to commence with the superstructure works on site. Most of the respondents also responded that the sub-contractor is considered as important party which should involve in the implementation of IBS due to the reason that they have the responsibility to certain IBS construction works with the mean score of 3.70 .

The lowest position is the project manager with the lowest mean score of 3.35. There are some of the respondents responded that the project manager is not important to the implementation of IBS. However, it can be found that most of the respondents responded that the project manager is an important party that should involve in the implementation of IBS. Project managers are considered as important because they are responsible in monitoring the work progress from inception stage until the building is completed. The position for each 
construction party has been presented in the form of bar chart which shown in Figure 22.

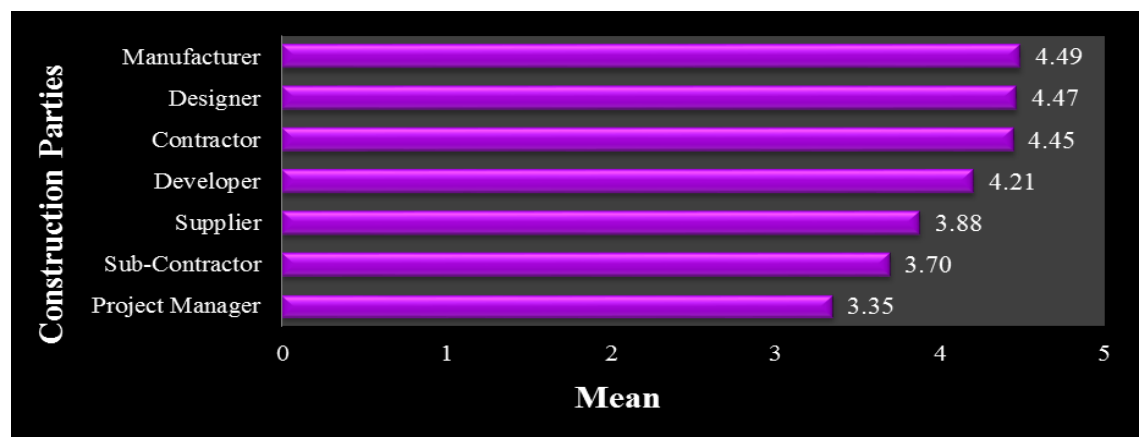

Figure 5. Construction parties should involve in IBS

Barriers to the implementation of IBS

Figure 6 indicated the results for the barriers to the implementation of IBS in Petaling Jaya, Selangor, Malaysia based on the level of agreement from the respondents. The barriers shown in Figure V have been analyzed and ranked according to the average mean score. The primary barrier that restricts the usage of IBS is poor skilled and knowledge of workers which ranked in first position with the average score of 4.42. IBS requires high skill and professional workers to operate the advanced technology machineries for installing and assembling the various types of standardized precast components on site. However, there is shortage of high skilled workers especially due to lack of interest of local workers and lack of opportunity given by the workers to undergo with IBS training program. The second highest average mean score is the barrier of supply chain issue with the score of 4.12. Most of the respondents agreed that supply chain issue is considered as a critical barrier due to lack of communication and integration among the construction stakeholders throughout the project period which could delay or late of supply and discrepancy of design concept of the building elements. Next, the barrier that ranked in the third position is improper planning of design with the average mean score of 3.84 . 
Thus, it can be justified that the causes of improper planning and design are due to the poor connection defects among the precast components which cause water leakage of the building and underestimate the important of accuracy in setting out the alignment and levelling of the bases.

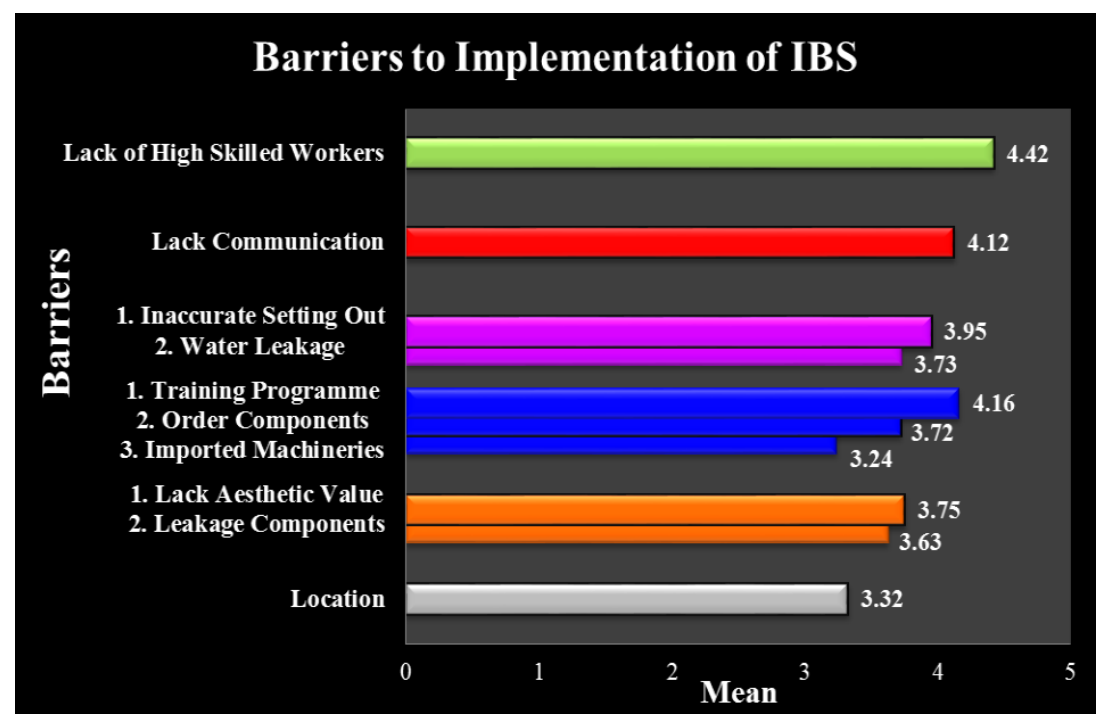

Figure 6. Barriers to implementation of IBS

Table 1. Reliability statistics for elements of responsibilities of construction parties to ibs, parties should involve in ibs and barriers in implementing IBS.

\section{Reliability Statistics}

\begin{tabular}{|r|r|}
\hline $\begin{array}{l}\text { Cronbach's } \\
\text { Alpha }\end{array}$ & N of Items \\
\hline .913 & 28 \\
\hline
\end{tabular}


Table 1 showed the reliability statistics for elements under the responsibilities of construction parties to IBS, parties that should involve in IBS and barriers in implementing IBS. The value of Cronbach's Alpha Coefficient shown in Table 1 is 0.913 which exceeding 0.650 . Thus, it can be concluded that the scales are reliable with the sample.

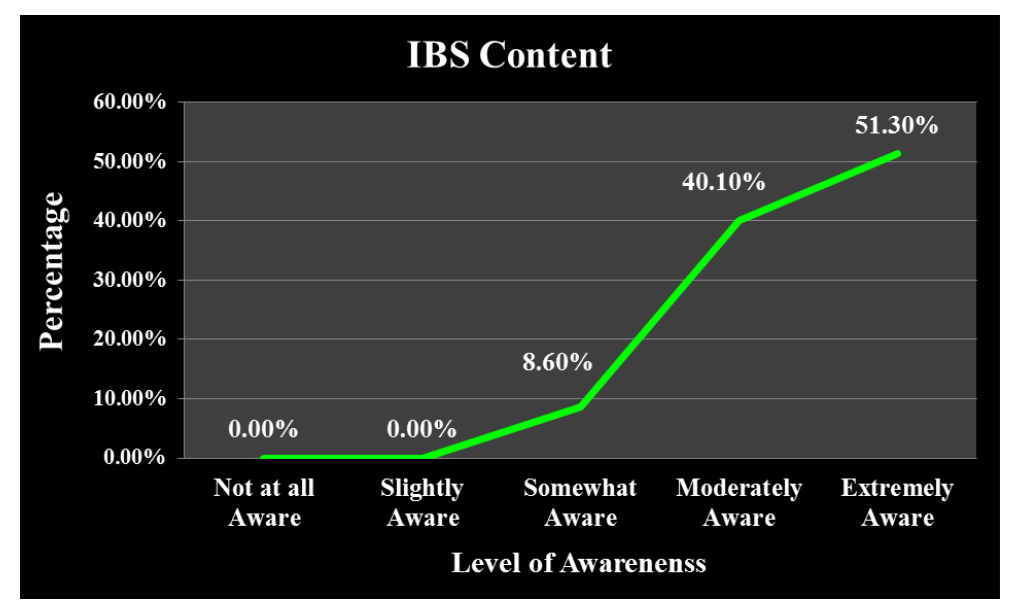

Figure 7. IBS content encouraged by the government using IBS at least for public projects and private projects

Figure 8 indicated the results for the level of awareness from the respondents based on the IBS content encouraged by the government using IBS at least $70 \%$ for public projects and $50 \%$ for private projects. The results proved that there are $51.30 \%$ of the respondents extremely aware on this current issue, followed by $40.10 \%$ of the respondents moderately aware and only $8.60 \%$ of the respondents somewhat aware for the usage of IBS content. Besides, none of the respondents are not at all aware and slightly aware of the IBS content for public and private projects. Therefore, it can be concluded that majority of the respondents are aware for the current issue of IBS content in which the government encourage using IBS at least $70 \%$ for public projects and $50 \%$ for private projects. 


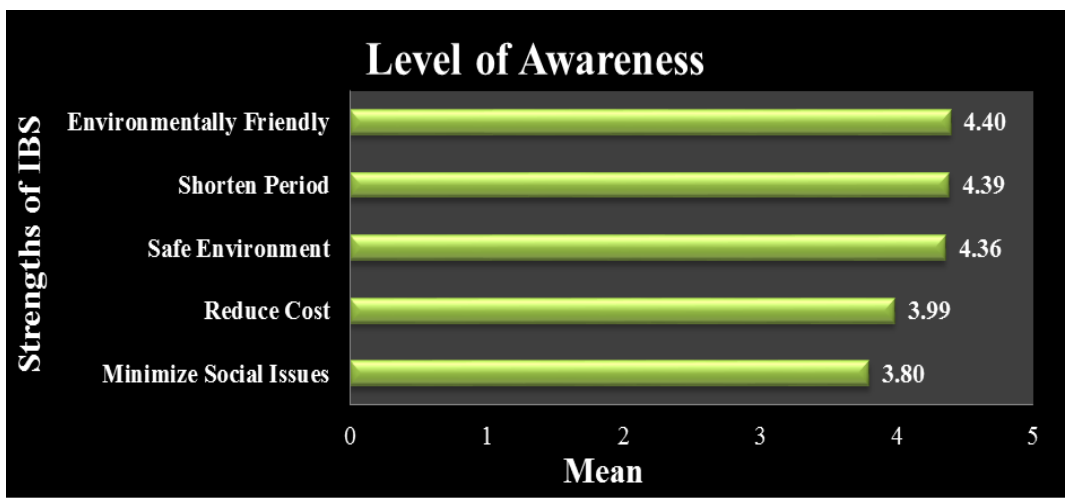

Figure 8 . Strengths of using IBS in construction industries

Table 2. Reliability statistics for elements of ibs content encouraged by the government using IBS for public projects and private projects and strengths of using IBS in construction industries

\section{Reliability Statistics}

\begin{tabular}{|r|l|}
\hline $\begin{array}{l}\text { Cronbach's } \\
\text { Alpha }\end{array}$ & $\begin{array}{l}\text { N of } \\
\text { Items }\end{array}$ \\
\hline .897 & \\
\hline
\end{tabular}

Table 2 showed the reliability statistics for of IBS content encouraged by the government using IBS for public projects and private projects and strengths of using IBS in construction industries. The value of Cronbach's Alpha Coeficient obtained is 0.897 which exceeded 0.650. Thus, the scales are reliable with the samples. 
Strategy to maximize the IBS implementation in construction project.

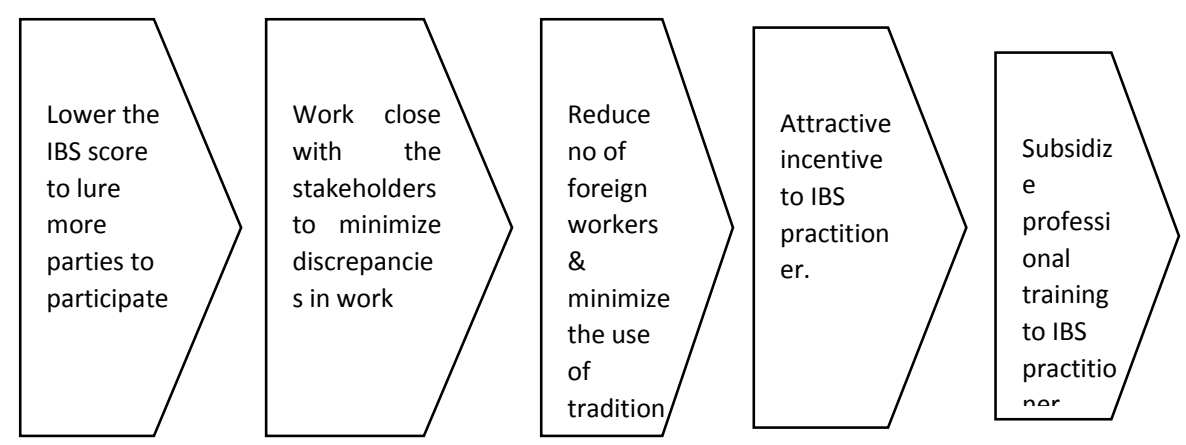

Figure 9. Strategies to maximize the IBS implementation in construction project

Reliability Statistics

\begin{tabular}{|r|r|}
\hline $\begin{array}{l}\text { Cronbach's } \\
\text { Alpha }\end{array}$ & N of Items \\
\hline .681 & 5 \\
\hline
\end{tabular}

Table 3. Strategy to maximize the implementation of IBS

Table 3 showed the reliability statistics for strategies to maximize the IBS implementation in construction project. The value of Cronbach's Alpha shown in Table III is 0.681 which exceeded 0.650 . Thus, the scales analyzed are reliable with the samples.

\section{Conclusion And Recommendation}

The strategies mentioned in the questionnaire surveys have been responded by the respondents based on the level of importance and agreement for each strategy. Based on the results analyzed, there are two strategies are considered as the most significant strategies that can maximize the usage of IBS. The strategy for the reduction of IBS score $(70 \%$ of IBS) for the Contractors with lower IBS experiences indicated as the most important strategy that can maximize the usage 
of IBS by achieving the highest mean score among the other strategies. The government should aware the condition for the lower grade of Contractors with low experiences in IBS projects and financial ability faced by them by lowering the IBS score of $70 \%$ for IBS projects. The reduction of IBS score definitely enable the lower grade of Contractors have the opportunity to commence with the small or medium IBS projects and the burden of financial liquidity will be greatly reduced from the Contractors.

The second important strategy is the workers have to be given opportunity to undergo IBS training programme to produce high skilled workers in order to prevent poor image of IBS products. The shortage of high skilled workers in the construction market definitely affects the usage of IBS implemented in construction industry. This is the critical issue facing by the local construction industries currently. Due to lack of high skilled workers, the production of IBS will be greatly affected such as the problems of leakage and low quality of building which will influence the perspective of the clients to invest on the IBS projects. Therefore, this negative impact has to be overcome by the cooperation from the government and the private sectors. The organizations should have more incentive to provide opportunity to their workers to attend the IBS skills training programme or workshop in order to produce more high skill workers which could contribute and increase the usage of IBS implemented in local construction industries.

\section{Recommendation}

There are some of the recommendations for the construction industry which are listed below:

1. Government should reduce $70 \%$ of IBS score to lower Grade and experience of Contractors to enable them to commence with small or medium projects by adopting IBS method. Reduction of IBS score of could minimize the burden of financial issue faced by most of the small Contractors.

2. The subject of IBS education has to be included in the programme of construction and engineering which offered in colleges and universities. The future construction practitioners 
should have the IBS knowledge before step out to the society to enhance their awareness and understanding on IBS.

3. Contractors and developers have to provide opportunity to their workers to undergo the IBS skills training programme and workshop especially for installer and crane operator. The workers with skills and knowledge in IBS construction will minimize the common problems occur and produce safe working environment.

4. Value Management workshop has to be effectively performed by the construction stakeholders in the early design stage to minimize the issues such as discrepancy in the designation of IBS components and enhance the integration among the stakeholders to work closely.

\section{References}

- $\quad$ Bing, L., Kwong, Y.W., \& Hao, K.J. (2001). Seismic behaviour of connection between precast concrete beams. CSE Research Bulletin, No. 14. Malaysia.

- Budget 2017: Funds to repair schools a relieffor Sarawak. (2016, October 21). New Straits Times Online.

- Construction Industry Development Board Malaysia. (2003). IBS Roadmap 2003-2010, CIDB Malaysia, Kuala Lumpur.

- Construction Industry Development Board Malaysia. (2005). IBS DIGEST 1, CIDB Malaysia, Kuala Lumpur.

- Construction Industry Development Board Malaysia. (2005). IBS Survey 2005: Survey on Malaysian Architects, CIDB Malaysia, Kuala Lumpur.

- Construction Industry Development Board Malaysia. (2009). Industrialised Building System (IBS): 
Implementation Strategy from $R \& D$ Perspective, CIDB Malaysia, Kuala Lumpur.

- Construction Industry Development Board Malaysia. (2010). Manual for IBS Content Scoring System (IBS SCORE), CIDB Malaysia, Kuala Lumpur.

- Construction Industry Development Board Malaysia. (2011). IBS Roadmap 2011-2015, CIDB Malaysia, Kuala Lumpur.

- Construction Industry Development Board Malaysia. (2015). Construction Industry Transformation Programme, CIDB Malaysia, Kuala Lumpur.

- Hashim, Mohd. Suffian. (1998). “The Industrialised Construction System - Pengalaman (The Experience of) PKNS Engineering \& Construction Berhad (PECB) "' in Colloquium on Industrialised Construction System, CIDB Malaysia, Kuala Lumpur.

- $\quad$ Kamar, K. A. M., Alshawi, M. \& Hamid, Z. A. (2009). Barriers to Industrialised Building System (IBS): The Case of Malaysia. $\mathrm{BuHu}$ 9th International Postgraduate Research Conference (IPGRC) (Eds., Alshawi, M., Ahmed, V., Egbu, C. and Sutrisna, M.), Salford, UK.

- $\quad$ Kamar, K., Hamid, Z., \& Din, I. (2012). The adoption of Industrialised Building System (IBS) construction in Malaysia. Gerontechnology, 11(2), 175. Retrieved 20 August, 2016, from http://dx.doi.org/ http://dx.doi.org/10.4017/gt.2012.11.02.634.00

- $\quad$ Nawi, M. N. M., Elias, E.M., Hamid, M. S. A. \& Yusoff, M. N. (2005). A Study of IBS Formwork Usage in the Malaysian 
Construction Industry. Proceeding in National Seminar on Engineering Support Course, University Malaysia Perlis, Malaysia.

- $\quad$ Nawi, M. N. M., Lee, A., \& Nor, K. M. (2011). The Built \& Human Environment Review, 4. Barriers to implementation of the industrialised building system (IBS) in Malaysia, 4(17590574), 22-35.

- Rahman, A. B. A, Omar, W. (2006). Issues and Challenge in the Implementation of IBS in Malaysia. Proceeding of the 6th Asia Pacific Structural Engineering and Construction Conference (ASPEC 2006), 5-6 September. Kuala Lumpur, Malaysia.

- Sumadi, S. R. (2001). "Promotion strategy and future research and development on IBS", National Seminar on Industrialised Building System, Construction Industry Development Board (CIDB), Kuala Lumpur.

- Thanoon, W. A. M., Peng, L. W., Abdul Kadir, M. R., Jaafar, M.S. and Salit, M.S. (2003). The Experiences of Malaysia and Other Countries in Industrialised Building System in Malaysia. Proceeding on IBS Seminar, UPM, Malaysia.

- Trikha, D. N. and Ali A. A. A. (2004). Industrialised Building System (Fist ed.), Kuala Lumpur, Universiti Putra Malaysia Press. 